Anuario Latinoamericano Ciencias Políticas

y Relaciones Internacionales

vol. 1, 2014

p. $155-184$

\title{
El desarrollo de la ciencia política en Argentina, Brasil y México: construyendo una mirada comparada ${ }^{1}$
}

\author{
Pablo Bulcourf \\ UNIVERSIDAD DE BUENOS AIRES, \\ ARGENTINA \\ $\triangle$ pablo_bulcourf@yahoo.com.ar \\ Enrique Gutiérrez Márquez \\ UNIVERSIDAD IBEROAMERICANA DE MÉXICO \\ Nelson Cardozo \\ UNIVERSIDAD DE BUENOS AIRES, \\ ARGENTINA
}

\begin{abstract}
RESUMEN
Este artículo analiza la historia de la ciencia política en Argentina, Brasil y México en perspectiva comparada, pretendiendo dar cuenta del proceso de construcción disciplinar centrado en estos últimos cincuenta años donde se registran indicadores de autonomización, especialización y profesionalización de la ciencia política. El esquema propuesto estudia la vinculación de la constitución del campo científico de la ciencia política con los procesos culturales, sociales, económicos y políticos que lo han orientando y condicionado sobre estos años.
\end{abstract}

PALABRAS CLAVE: ciencia política, historia de la ciencia, América Latina, Argentina, Brasil, México.

\section{SUMMARY}

This article analyzes the history of political science in Argentina, Brazil and Mexico from a comparative viewpoint. Its intention is to give an account of the process of development of this discipline over the last fifty years, during which the indicators of empowerment, specialization and professionalization of political science have been recorded. The proposed scheme examines the links between the constitution of the scientific field of political science and the cultural, social, economic and political processes that have oriented and conditioned it over the years.

KEYWORDS: political science, history of science, Latin America, Argentina, Brazil, Mexico.

\footnotetext{
1 Los autores quieren agradecer los comentarios y aportes de Cristian Pereira y Lucas Jolias.
} 


\section{Introducción}

Este artículo intenta dar cuenta del desarrollo de la ciencia política en los tres países de mayor tamaño sociodemográfico de América Latina: Argentina, Brasil y México, estableciendo algunos parámetros comparativos entre ellos.

Durante los últimos treinta años hemos asistido a un fuerte crecimiento de la ciencia política en América Latina, aunque esto con escalas diferenciadas en los países de la región. La elección de estos casos articula la envergadura y gravedad de los tres Estados más relevantes, en los que se registran indicadores claros que expresan esta afirmación. Sin embargo, sus particularidades nos muestran matices interesantes en el tipo de ciencia política que se ha ido construyendo, estando esto en parte vinculado al propio contexto político y social y al "modelo" de país que fueron orientando los sucesivos gobiernos a lo largo de la última mitad del siglo XX. Si bien son campos diferenciados, la matriz político-cultural y económica ha moldeado, orientado, posibilitado y restringido la construcción del campo científico-intelectual de la ciencia política. Esta afirmación no debe pretender establecer correlaciones directas ni reduccionismos analíticos ya que se trata de una estructuración social compleja y dinámica en donde se articulan aspectos nomotéticos pero también ideográficos. Esta concepción de la propia ciencia social es orientadora de nuestro trabajo y de las estrategias metodológicas que hemos estado siguiendo en los últimos años.

En el período señalado se han ido creando numerosas carreras de grado y posgrado; desarrollado programas de investigación sobre temáticas centrales de la disciplina y sobre aquellos aspectos particulares de cada país. La producción editorial ha tenido un despegue y consolidación exponencial, lo que se ha expresado en la publicación de numerosos libros de autor, compilaciones $y$, principalmente, series de revistas científicas especializadas que han ido incorporando reglas de evaluación cada vez más rigurosas para seleccionar sus artículos, aunque sin por ello dejar de lado cierta orientación de corte teóricoideológico-metodológico en el establecimiento de su política editorial, si bien muchas veces esto no se expresa de manera explícita.

Por otra parte, se ha venido registrando una constante y creciente transferencia de conocimientos de la ciencia política a otros ámbitos de la vida social, entre ellas la propia actividad política como también los sucesivos programas de reforma del Estado y de calidad institucional. Varios organismos internacionales han ocupado un papel central en la incorporación de profesionales de las ciencias sociales en sus planteles. La participación de los politólogos también se ha incrementado en la actividad empresarial, principalmente vinculados a lo que suele denominarse relaciones institucionales. A nivel de los congresos, el número de asesores que detentan un título de ciencia política es cada vez mayor, un campo que estuvo dominado ampliamente por la abogacía en otros períodos. En las organizaciones de la sociedad civil y en diferentes ONG, la incorporación de politólogos crece de manera constante. El campo de la opinión pública, la construcción de campañas electorales y la comunicación 
política son también espacios en donde los licenciados en ciencia política van tomando roles centrales.

La propia formación y especialización de los politólogos se ha visto apuntalada por un doble juego en la formación de posgrado; por un lado varios de ellos recibieron sus estudios en los EEUU y Europa y, por otro, se fueron desarrollando en la propia región programas de maestrías y doctorados, algunos de ellos de elevada calidad académica.

Esto nos abre un nuevo interrogante, principalmente teniendo en cuenta las enormes asimetrías geográficas y socioeconómicas que persisten en la región: ¿será este crecimiento claramente demostrable en términos cuantitativos un verdadero desarrollo disciplinar? ¿Hasta qué punto estos indicadores tomados en su expresión numérica en el fondo esconden esas asimetrías y terminan profundizándolas? Esto nos lleva a plantearnos un enorme debate en torno al tipo de ciencia política que se ha venido estableciendo en la región y, de alguna manera, sobre su propia utilidad social. Esto también sucede dentro de los estudios sobre historia y enseñanza de la ciencia política, ya que estos no son "inocentes": la forma en que narramos nuestra propia historia, aquello que consideramos importante y destacado y lo que dejamos de lado tiene un enorme efecto en la construcción del prestigio, el otorgamiento de fondos y la orientación de la propia investigación y sus posibilidades de transferencia. Muchas veces, los propios politólogos cometemos el "error" de hacer un relato de nuestra disciplina aparentemente impermeable al propio poder que es la materia básica de nuestro objeto de estudio; somos ciegos frente a estas relaciones dentro de la propia comunidad como a su vinculación con las otras esferas sociales, entre ellas la propia política. Por esta razón, es necesario elaborar una mirada más profunda y reflexiva sobre nuestras prácticas, animarnos a preguntarnos por la "política de la ciencia política". Algunos estudios recientes han comenzado a transitar por este camino, por cierto nada fácil ya que se trata del análisis crítico sobre nosotros mismos. Los recientes trabajos de María de los Angeles Fernández Ramil, Cecilia Lesgart, Cristobal Grebe Ramírez, Paulo Ravecca, Sergio Ángel Baquero, Julián Caicedo Ortíz, Cecilia Rocha y Julián Cuellar Argote se han ido orientando por ese sendero incorporando algunos interrogantes y el aporte de otras áreas fuertemente interdisciplinarias, como así también el llamado enfoque de la colonialidad del saber. Estos intentos se fueron cristalizando en los debates que se llevaron a cabo en el marco del III Congreso de Ciencia Política que organizó la Asociación Colombiana de Ciencia Política durante 2014 en las ciudades de Cali y Popayán $y$, durante el mismo año, en los encuentros llevados a cabo en las Jornadas específicas en Montevideo como en México en ocasión del 50 Aniversario de la Universidad Iberoamericana. Algunos especialistas se propusieron una serie de orientaciones en torno a los propios estudios sobre el campo disciplinar que se ha denominado Manifiesto de Popayán. Este trabajo intenta, en un espacio muy acotado, incorporar algunos de estos elementos para continuar con esta tarea de conocernos a nosotros mismos.
El desarrollo de la ciencia política en Argentina, Brasil y México: construyendo una mirada comparada

Pablo Bulcourf Enrique Gutiérrez Márquez Nelson Cardozo 


\section{Esbozo del área de estudios sobre el desarrollo de la ciencia política en América Latina}

El desarrollo mencionado ha dado paso a una creciente preocupación por la historia de la ciencia política en la región. Esto comenzó primero a nivel nacional y, en los últimos años, se ha comenzado a trabajar en pequeños aportes comparados. Como señalan la mayoría de los sociólogos del conocimiento y los historiadores de la ciencia, la reflexión sistemática sobre los campos disciplinares realizada por los propios cultores de una determinada ciencia es uno de los indicadores de su propia evolución. La pregunta por la propia historia nos revela la existencia de ésta y la necesidad de ser pensada. ${ }^{2}$

En el año 2005, la "Revista de Ciencia Política” publicada por la Universidad Católica de Chile dedicó todo un número especial a dar cuenta de la ciencia política en América Latina. Por otra parte, en los diferentes congresos de ciencia política organizados por las asociaciones regionales, como la SAAP, la ABCP, la AUCyP, la ACC, la ACCPOL y la AMECIP, se fueron registrando ponencias y paneles especiales de reflexión en torno al desarrollo y enseñanza de la disciplina; creándose en muchas de ellas grupos de trabajo específicos en la temática.

Por su parte, la "Revista Argentina de Ciencia Política" publica en su número 13/14 uno de los primeros trabajos comparados: Del Centenario al Bicentenario: algunas reflexiones sobre el desarrollo de la ciencia política en los países del Cono Sur, escrito por Nelson Cardozo (Carodozo 2010); simultáneamente David Altman publica su estudio Where is Knowledge Generated? On the Productivity and Impact of Political Science Departaments in Latin America en la revista "European Political Science" (Altman 2011). En el marco del IV Congreso de ALACIP en Costa Rica, se realizó una mesa de trabajo sobre el estado de la ciencia política latinoamericanista en Europa y Estados Unidos, en donde participaron destacados académicos de la región. En el Congreso realizado en ocasión de los 50 años de FLACSO en Quito en el año 2007, se celebró una mesa similar sobre los estudios latinoamericanistas en ciencia política. Con posterioridad, durante el V Congreso de ALACIP, realizado en Buenos Aires en 2010, se demostró un interés creciente, tanto en la presentación de trabajos como en la dedicación de una de sus sesiones plenarias a dar cuenta del desarrollo de la ciencia política en la región ${ }^{3}$, lo que se profundizó en el VI encuentro, celebrado en 2012 en la

2 Un trabajo muy interesante sobre el desarrollo de la ciencia política en los EEUU, Europa y algunos países anglófonos lo constituye la compilación The Development of Political Science. A comparative Surrvey realizada por David Easton, John Gunnell y Luigi Graziano (Easton, Gunnell y Graciano 1991).

3 En dicho congreso, el entonces Secretario General de la ALACIP, Glaucio Soares, apoyó la propuesta presentada por el politólogo mexicano, Víctor Alarcón Olguin, en el marco de la reunión del Comité Ejecutivo de la ALACIP, en el punto dedicado a la creación de nuevos grupos de investigación, para impulsar uno que se dedicara al estudio de la historia disciplinar de la región, lo que se formalizó en congreso siguiente de la asociación. 
ciudad de Quito, donde se dio paso a la creación del Grupo de Investigación sobre Historia de la Ciencia Política en América Latina (GIHCIPOLALALACIP $)^{4}$, el que amplió considerablemente su cantidad de miembros y ponencias un año después, durante el VII Congreso llevado a cabo en Bogotá, circunstancia que permitió la realización de un amplio seminario sobre la temática en la Universidad Sergio Arboleda. Por su parte, la revista "Política. Revista de Ciencia Política" del Instituto de Asuntos Políticos de la Universidad de Chile pública cuatro artículos sobre la historia disciplinar en Argentina, Chile, México y Uruguay. En 2013, el Consejo Mexicano de Investigación en Ciencia Política (COMICIP) ${ }^{5}$ va a desarrollar, en forma conjunta con la IPSA, uno de los eventos más importantes tendientes a analizar la historia y desarrollo de la ciencia política tanto en América Latina como en el resto del mundo, contando con destacados participantes del ámbito latinoamericano, anglosajón y europeo.

Durante el año 2014 se llevaron a cabo varias actividades vinculadas al estudio específico de la historia y desarrollo disciplinar; la primera de ella fue organizada en forma conjunta por la Universidad de la República del Uruguay y el grupo de estudio específico de ALACIP. Colegas de toda la región se reunieron en Montevideo para intercambiar trabajos e ideas en torno a esta área de reciente constitución. Posteriormente, en México, se realizó un simposio específico en San Luis Potosí, en el cual se analizó el devenir de los estudios en el país azteca. Durante el mes de octubre, en ocasión del 50 Aniversario de la Universidad Iberoamericana de la Ciudad de México, se realizaron una serie de eventos que permitieron una profundización sobre el desarrollo e historia de la disciplina en Argentina, Brasil, Chile, Colombia, Uruguay y México.

Para el campo de los estudios comparados sobre el desarrollo disciplinar, en 2014, Fernando Barrientos del Monte publicará una de las primeras obras editadas con una fuerte intención de establecer diferencias y similitudes dentro de la ciencia política latinoamericana, apareciendo su libro Buscando una identidad. Breve historia de la Ciencia Política en América Latina (Barrientos 2014). Desde Europa, la revista "Iberoamericana" dedicó su Foro de Debate a la discusión sobre los desarrollos de la ciencia política latinoamericana y sus interrogantes en su número 56 del mismo año. Estas recientes publicaciones y los debates sucedidos en el marco de los congresos nacionales y varias actividades específicas nos van señalando la importancia que paulatinamente han ido adquiriendo este tipo de investigaciones que intentan arrojar un poco de luz sobre la actividad politológica latinoamericana.

4 La mesa directiva del Grupo quedó integrada por los profesores Víctor Alarcón Olguín (México), José Viacava Gatica (Chile) y Pablo Bulcourf (Argentina).

5 Consejo Mexicano de Investigación en Ciencia Política, más información disponible en: http://www.comicip.org.mx/
El desarrollo de la ciencia política en Argentina, Brasil y México: construyendo una mirada comparada

Pablo Bulcourf Enrique Gutiérrez Márquez Nelson Cardozo 

lineamientos teóricos básicos

Las ciencias sociales constituyen una actividad humana de carácter cognitivo que se desarrolla en un contexto sociohistórico, esto quiere decir que su principal objetivo - y no el único - es la producción de conocimientos sobre cierta porción de "realidad" que define como "social" y "política" y que constituye su objeto de estudio (Bulcourf 2007). Al ser un quehacer humano es histórico y posee su "propia historia". Al ahondar como práctica "las propias prácticas de las personas", se entrelaza en una doble hermenéutica en donde sujeto y objeto de conocimiento no pueden ser tajantemente separados; situación que comparte con las otras ciencias sociales, y en parte, con toda reflexión humana (Giddens 1987).

La actividad científica sistemática producida desde la modernidad se encuentra anclada dentro de lo que comúnmente denominamos "comunidad científica", la cual presenta, acorde a cada disciplina y momento histórico, diferentes grados de heterogeneidad u homogeneidad. La diversidad es un rasgo distintivo de todo quehacer científico-académico. Esto no debe ser visto como un defecto o retraso en el desenvolvimiento de la actividad cognitiva, sino algo propio de su acontecer y desarrollo. Por otro lado, en disciplinas que reflexionan sobre la estructura social, el poder, las instituciones y los sistemas de dominación que han implementado los hombres, todo intento de hegemonía cognitiva es perjudicial para comprender la complejidad de lo político-social y tiende a callar voces disidentes (Bourdieu 2003 y 2008).

Toda comunidad científico-académica se encuentra inserta en una determinada realidad social. Por esta razón, es fundamental incorporar estos patrones para su estudio. Muchos expertos han señalado dos dimensiones para este análisis: lo que han denominado la "historia interna", es decir, las características propias del grupo científico y sus quehaceres y peculiaridades, y la "historia externa", la cual se refiere a los condicionantes mencionados. No puede desconocerse que toda la historia del desarrollo de las ciencias sociales en América Latina se ha visto truncado y condicionado por el régimen político (Trinidade, 2007). Para dar cuenta del desarrollo de un campo científicoacadémico se propone abordar los siguientes aspectos:

- El nivel de los sujetos, entendidos como las personas y grupos, portadores de su biografía, accionar y valores fundantes. Son agentes sociales en tanto productores y reproductores de sus prácticas con diferentes grados de conciencia y libertad, pero condicionados históricamente. Los actores son constructores de su subjetividad. Estos no sólo actúan en el nivel del individuo, sino que en la actividad científica se suele hablar también de comunidades, es decir, los llamados equipos de trabajo o investigación.

- El nivel institucional, en tanto ámbitos o espacios en los que se producen y reproducen las prácticas. Las instituciones proveen de marcos de conten- 
ción, limitación y recursos, como así también la presencia diacrónica de las mencionadas prácticas. La comunidad científica posee sentido e identidad en tanto existan las instituciones y su reproducción. Entre los tipos de estas, dependiendo de cómo se va estructurando la comunidad científica en cada país o región, éstas pueden ser de enseñanza, de investigación, o privilegiar algún papel sobre el otro.

- El nivel de la producción y su comunicabilidad, entendidos como los conocimientos que genera y comunica la comunidad científica. Los que se "materializan" en publicaciones, patentes, tecnologías, entre otros. En el campo de las ciencias sociales serían las publicaciones en revistas científicas, los libros especializados, las comunicaciones y ponencias en congresos y jornadas, los informes de investigación y documentos de trabajo. Pero también son importantes las transferencias de conocimientos realizadas hacia el Estado, las empresas o entidades de la sociedad civil.

- El nivel de las asociaciones y redes, entendidas como los lazos interinstitucionales y de vinculación entre la propia comunidad científica y, a veces, con otros ámbitos de la vida social. La cantidad de éstas y su densidad son elementos centrales para analizar los grados de institucionalización de una disciplina. Un ejemplo de ello lo constituyen las asociaciones científicas, verdaderas redes de instituciones y de actores.

Cuando se particulariza una determinada disciplina en sus coordenadas históricas y geográficas no se puede dejar de tener en cuenta las peculiaridades de cada país o región. Las dimensiones geográficas y demográficas condicionan fuertemente el grado y tipo de desarrollo de una disciplina, más aún en el campo de las ciencias sociales.

\section{Tres grandes tigres}

Cualquier investigación comparada que se pretenda rigurosa debe explicitar los criterios de selección de los casos. Por ello, la pertinencia de comparar estos países de América Latina se corresponde a la lógica de "sistemas similares" y, por consiguiente, se parte del supuesto que estos cinco países comparten algunas propiedades que se toman como constantes que son las denominadas variables de control. A partir de una primera indagación se presentan algunos indicadores para pensar que ello es así.

Los tres países se encuentran en América Latina, comparten desarrollos históricos similares (colonización iberoamericana, procesos independentistas contemporáneos, matrices de desarrollo socioeconómico parecidos, regímenes autoritarios durante el siglo XX, entre otros aspectos), culturales y demográficos, por señalar algunas dimensiones. No obstante ello, el aspecto que se considera más importante a los efectos de aislar variables es que los tres países tienen un similar grado de desarrollo humano. Según el Índice de Desarrollo
El desarrollo de la ciencia política en Argentina, Brasil y México: construyendo una mirada comparada

Pablo Bulcourf Enrique Gutiérrez Márquez Nelson Cardozo 
Humano de Naciones Unidas ${ }^{6}$, los tres países pertenecen al grupo de países de "Desarrollo Medio y Alto".

Por otro lado, son países de gran tamaño en términos de superficie y cantidad de población, encontrándose Brasil y México entre los más poblados del mundo superando los 100 millones de habitantes. Los tres países poseen una economía desarrollada con un sector secundario y terciario importante, permitiendo sus características demográficas un mercado interno destacado y son principalmente exportadores de materias primas.

Desde el plano político, son regímenes presidencialistas de carácter federal encontrándose sus constituciones inspiradas en parte en el modelo norteamericano; aunque Brasil tuvo un período monárquico con el Imperio.

En la Tabla 1 se muestran algunos aspectos generales básicos de los países estudiados.

\section{El nivel institucional}

Una primera aproximación al estudio comparado sobre el desarrollo de la ciencia política tiene que hacer énfasis en los espacios institucionales de transmisión del conocimiento. Atendiendo esta variable no se puede dejar de mencionar como fueron desarrollándose los cursos de ciencia política, tanto de grado como de posgrado. Cada historia nacional presenta divergencias sustantivas, especialmente en relación a los procesos de creación de instituciones de enseñanza de la ciencia política.

En primer lugar, en Argentina y México, se observa un sendero que se corresponde con los demás países de América Latina, dado que se crearon primero carreras de grado, luego maestrías y, finalmente, doctorados. Por el contrario, en Brasil, la ciencia política es una especialización que se desarrolla en el nivel de maestría y doctorado, con posterioridad a las licenciaturas en ciencias sociales y su desarrollo ha sido principalmente en el posgrado. Esto tiene una especial incidencia en la conformación de la llamada identidad profesional, la manera en que se constituye su asociación de politólogos y el tipo de profesionalización del campo científico.

En la década de 1920, en Argentina, se comenzó a dictar en la Universidad del Litoral, sede Rosario, la Licenciatura en Derecho Consular, creada

6 El Índice de Desarrollo Humano (IDH) fue creado en 1990 a través del Programa de las Naciones Unidas para el Desarrollo (PNUD). El objetivo era poder medir los progresos generales de un país en tres dimensiones básicas del desarrollo humano. Para cada dimensión habían elegido una variable que la representaba. El IDH reduce los tres indicadores básicos a un valor que indica la distancia que el país tiene que avanzar hasta llegar al máximo posible. Este índice va de 1 (el mejor) a 0 (el peor). Los países se clasifican según su IDH en tres grupos:1) países con desarrollo humano alto: con valores del IDH de 0,800 y superiores; 2) países con desarrollo humano medio: con valores entre 0,500 y 0,$799 ; 3)$ países con desarrollo humano bajo: con valores inferiores a 0,500 . 
en 1921 (Bulcourf 2008a). Las actividades tuvieron lugar en la Facultad de Ciencias Económicas. En 1927, se crearon dos doctorados: uno, que seguía la línea planteada en los estudios de grado referidos más arriba, que pasó a llamarse "Diplomacia", y otro con la denominación "Ciencia Política" (Bulcourf y D’Alessandro 2003). Estas instituciones estuvieron estrechamente ligadas a las concepciones jurídicas, más que a los debates de la ciencia política que se desarrollaba, sobre todo desde finales del siglo XIX, en los Estados Unidos. Esto quiere decir que, si bien se denominaban "ciencias políticas", los enfoques, problemas y paradigmas no se correspondían con el mainstream vigente en lo que se puede denominar como "historia universal disciplinar".

Sin embargo, los estudios políticos se fueron desarrollando en otras instituciones, dado que en 1927 se creó en la Facultad de Filosofía y Letras de la Universidad de Buenos Aires, el Instituto de Sociología, que tendría solamente ese rótulo formal. Recién en la década de 1940 se generó un resurgimiento de las ciencias

\begin{tabular}{|c|c|c|c|}
\hline País & Argentina & Brasil & México \\
\hline Superficie $\left(\right.$ en $\mathrm{km}^{2}$ ) & 2.780 .400 & 8.514 .877 & 1.964 .375 \\
\hline $\begin{array}{l}\text { Población* (en millones } \\
\text { de habitantes (2012) }\end{array}$ & 42.192 .494 & 199.321 .413 & 114.975 .406 \\
\hline PBI (en millones de US\$) & 435.200 & 2.518 .000 & 1.185 .000 \\
\hline PBI per cápita (2011) & $\$ 17.700$ & $\$ 11.900$ & $\$ 14.800$ \\
\hline $\begin{array}{l}\text { Puesto del PBI en la } \\
\text { economía mundial }\end{array}$ & 22 & 7 & 12 \\
\hline $\begin{array}{l}\text { Posición en la tabla de } \\
\text { posiciones en el IDH (2012) }\end{array}$ & 45 & 84 & 57 \\
\hline $\begin{array}{l}\text { Coeficiente de Gini } \\
\text { (puesto mundial) al } 2012\end{array}$ & $0,375(75)$ & $0,519(139)$ & $0,470(120)$ \\
\hline Tasa crecimiento PBI (2011) & $8,9 \%$ & $2,7 \%$ & $4 \%$ \\
\hline Organización territorial & Federal & Federal & Federal \\
\hline $\begin{array}{l}\text { Año de transición } \\
\text { a la democracia }\end{array}$ & 1983 & 1985 & 2000 \\
\hline Sistema de gobierno & Presidencialista & Presidencialista & Presidencialista \\
\hline
\end{tabular}

* Corresponde casi en su totalidad a estimados originalmente elaborados por la Base de Datos Internacional (International Data Base, IDB) de la Oficina del Censo de los Estados Unidos (United States Census Bureau), redondeados de a miles.

Fuente: Elaboración propia sobre la base de los datos disponibles en: CIA, https://www.cia.gov/ library/publications/the-world-factbook/ y PNUD, http://hdr.undp.org/es/informes/mundial/ idh2011/
El desarrollo de la ciencia política en Argentina, Brasil y México: construyendo una mirada comparada

Pablo Bulcourf Enrique Gutiérrez Márquez Nelson Cardozo

Tabla 1.

Argentina, Brasil, México: algunos datos básicos. 
sociales de la mano de Ricardo Levene (h) y Gino Germani. De ello se puede inferir que se dio un proceso mucho más temprano en la sociología, en relación a la definición de una ciencia empírica, toda vez que fue generado un debate identitario en donde se enfrentaron dos grupos de cultores de la disciplina: por un lado, la sociología histórica, vinculada a la historia del pensamiento, a los grandes sistemas de la filosofía y la teoría social, versus la denominada sociografía, de corte empírico, asentado fuertemente en los datos, lo que definió dos posicionamientos que serían confrontados fuertemente décadas más tarde (Blanco 2006).

Esto se plasmó en el enfrentamiento entre el modelo científico y profesional de Gino Germani y el inicio de la carrera de sociología en la Universidad de Buenos Aires (UBA), opuesto a una sociología descriptiva y normativa, apartada del rigor metodológico y poco anclada en las discusiones internacionales de la sociología de aquella época. Esta última tendencia fue principalmente representada por Alfredo Poviña y sus discípulos en la Universidad Nacional de Córdoba (Bulcourf 2008b).

La vinculación entre los intelectuales y el peronismo marcó un hiato en este proceso de constitución de las ciencias sociales empíricas. Con la derrota del gobierno constitucional de Juan Domingo Perón se retomó este modelo, constituyéndose el lapso conocido como la edad de oro de la universidad argentina. No obstante, durante los años del justicialismo se va a producir un proceso modernizador, el cual contó con intelectuales que se encolumnaron en el proyecto. Dentro de estos pensadores es destacable la labor que realizó Arturo Enrique Sampay, el cual publicó la obra Crítica al Estado Liberal Burgués y su profusa obra Teoría del Estado. Más allá de ello, sería el encargado de la redacción de la Constitución del año 1949, presidiendo la Asamblea Constituyente.

En esa nueva Carta Magna se disponía como obligatoria la enseñanza de contenidos políticos y de identidad nacional en todos los estudios universitarios en la Argentina. En cumplimento con lo dispuesto por esta norma, en el año 1952, se crea la carrera de Ciencias Políticas en la Universidad Nacional de Cuyo, fusionándose con la de administración pública creada el año anterior; con un fuerte contenido orientado hacia la gestión pública. Como menciona Guardamagna (2008), la finalidad que tenía la carrera de ciencia política y administración pública era la formación de un estamento dirigente de la vida política, dentro de la concepción de Sampay.

Bajo esta línea de argumentación, resalta la importancia de la creación del programa de Cuyo como parte del proceso de formación de cuadros administrativos y políticos para la función pública. ${ }^{7}$ De este modo, queda claramente

7 Guardamagna menciona que la carrera de Cuyo "retoma una definición de Estado, un Estado que debe jugar un papel sumamente importante que claramente no es el del abstencionismo y por ello la Alta Burocracia como parte de la clase política a la cual Weber hace referencia, deberá poseer cualidades especiales. En este sentido, dirá que para conducir el país hacia la realización de los objetivos establecidos por la Constitución reformada de 1949 será menester formar un estamento dirigente que incluya a los burócratas de ese Estado gestor del bien común que instaura la Constitución" (Guardamagna 2008: 6). 
orientada dentro de lo que se puede denominar hoy en día capacitación para la función pública y no como la creación de un campo disciplinar tendiente a generar investigación empírica en la temática; similar a lo acontecido con la Escuela Libre de Ciencias Políticas creada para formar a la elite dirigente, en Francia.

Después del enfrentamiento sobre la educación superior en Argentina, que se plasmó en el lema "laica o libre", se permitió a las universidades privadas emitir títulos habilitantes, con lo que comienza el proceso de expansión de estas. Las dos primeras universidades creadas a partir de institutos anteriores van a ser en 1956 dos universidades jesuitas: Universidad del Salvador y la Universidad Católica de Córdoba. La primera incluyó la Licenciatura en Ciencia Política dentro de sus primeros cursos, mientras que la segunda lo hace en 1960 (Bulcourf y Cardozo 2010b).

La Licenciatura de Ciencia Política de la Universidad del Salvador fue la primera de su tipo en una universidad privada. En su reforma curricular de mediados de la década de 1960 se establecen dos orientaciones importantes: 1) sociología (para los que pretendían una visión más analítica y académica) y 2) administración pública (para aquellos orientados al sector público). Posteriormente, se desprenden estas dos ramas como carreras independientes, aunque administración pública rápidamente es suspendida como tramo de licenciatura independiente. A partir de la segunda reforma curricular implementada por Carlos Floria en 1969, se termina de estructurar la primer carrera de la disciplina ciencia política "en sentido estricto" con un claro eje en ciencia política empírica (marcado por las materias sistemática de la ciencia política, teoría política y sistemas políticos comparados) y un eje metodológico (el que incluía metodología de la investigación, matemática, estadística y seminario de investigación) (Bulcourf y Jolias 2006).

En relación a la ciencia política brasileña resulta necesario destacar el papel que tuvieron dos instituciones en su desarrollo: La Universidad Federal de Minas Gerais (UFMG) y el Instituto Universitario de Investigaciones de Rio de Janeiro (IUPERJ). ${ }^{8}$ Este proceso se encuentra muy vinculado al proceso de constitución del sistema de posgrado y a la matriz desarrollista de desarrollo económico que se consolida en la década de los años 60 en ese país. ${ }^{9}$

La Universidad de Minas Gerais permaneció en la órbita estadual hasta 1949, cuando experimentó una serie de reformas adoptando el nombre actual Universidad Federal de Minas Gerais (UFMG) en 1965; como parte de su ex-

8 En el desarrollo de las ciencias sociales en Brasil tuvo un rol central la Escuela Libre de Sociología y Política creada como entidad asociada a la Universidad de San Pablo en 1933 bajo la dirección de Roberto Simonsen (Cardozo 2014a, y 2014b).

9 Como sostiene Spina Forjaz "el despegue del proceso de institucionalización de la Ciencia Política en el país en los años 60 está vinculado a la constitución de un sistema de posgrado en la universidad brasileña, por un lado, y el establecimiento de agencias de fomento vinculadas a un sistema nacional de desarrollo científico y tecnológico, crecientemente vinculado a las políticas de planeamiento y desarrollo económico, por el otro." (Spina Forjaz 1997: 37).
El desarrollo de la ciencia política en Argentina, Brasil y México: construyendo una mirada comparada

Pablo Bulcourf Enrique Gutiérrez Márquez Nelson Cardozo 
pansión y diversificación creó nuevas unidades y cursos. Renovando la oferta académica se comienza a dictar en 1966 la Maestría en Ciencia Política. En 1968, la Reforma Universitaria impuso una profunda alteración a la estructura orgánica de la UFMG. De esta reforma resultó el desdoblamiento de la antigua Facultad de Filosofía en varias facultades e institutos. Surgieron, así, la actual Facultad de Filosofía y Ciencias Humanas, el Instituto de Ciencias Biológicas, el Instituto de Ciencias Exactas y sus respectivos ciclos básicos, el Instituto de Geociencias y las Facultades de Letras y de Educación. Es en este momento donde se crea el Departamento de Ciencia Política de donde pasa a depender el programa de Maestría en Ciencia Política que produjo el despegue de la disciplina en Brasil.

Spina Forjaz (1997) sigue la tesis planteada por Santos y Amorim Neto (2002), sosteniendo que el proceso de constitución de ciencia política estuvo condicionado por la gravitación del campo de las ciencias jurídicas y la sociología marxista, que le restaban autonomía al objeto de la ciencia política. ${ }^{10} \mathrm{En}$ 1969, la Universidad Cándido Mendes crea el Instituto de Investigaciones de Rio de Janeiro (IUPERJ) que incluyó dentro de su primera oferta académica la maestría en ciencia política. Esta institución se consolidó a mediados de la década del 1970 como un centro de investigación y enseñanza de punta en las ciencias sociales en el nivel de posgrado en el Brasil.

El derrotero de la institucionalización en la ciencia política brasileña fue llevado a cabo por los liderazgos de Wanderley Guilherme dos Santos en el IUPERJ y Fábio Wanderley Reis en la Universidad Federal de Minas Gerais, los cuales son figuras centrales en esa primera fase de la disciplina. "El Departamento de Ciencia Política de la Universidad Federal de Minas Gerais (DCP-UFMG) y el Instituto Universitario de Investigaciones de Rio de Janeiro, no por casualidad los cursos pioneros de posgrado en Ciencia Política; constituyen, a nuestro modo de ver, el núcleo central de la institucionalización de la disciplina en el Brasil. Fue un grupo de cientistas políticos vinculados a esas instituciones que asumió el liderazgo académico de ese proceso" (Spina Forjaz 1997: 42). ${ }^{11}$ Actualmente en Brasil encontramos 37 maestrías en el área de ciencia política y relaciones internacionales, de las cuales 31 son de corte académica y 6 de ellas profesionales, teniendo la denominación estricta de ciencia política 14 programas. En cuanto a los doctorados existen 17 en el área, siendo estrictamente 10 de ellos bajo la denominación de ciencia política (Cardozo 2014).

En México, se va dando un proceso similar al del resto de la región, experimentándose ese tránsito hacia la autonomización desde las otras ciencias

10 Santoa y Amorim Neto sostienen que "subyacente a la creación del máster en Ciencia Política, existía, entre el liderazgo intelectual vinculado a estos proyecto, una preocupación por la delimitación de las fronteras de su objeto. En este sentido, una disciplina y una escuela de pensamiento se levantaron en la condición de adversarios preferenciales: el derecho, por un lado, y la sociología marxista, por otro.” (Santos y Amorim Neto 2005: 102).

11 Traducción de los autores. 
sociales, con una especial atracción gravitatoria de la UNAM como centro de la producción de las ciencias sociales mexicanas, existiendo hacia 1970 únicamente cuatro centros que impartían cursos de grado en la disciplina. Así, "la ruta de formación de la Ciencia Política parte entonces de un desprendimiento de la ciencia jurídica define su vinculación concreta con la administración pública. El sello sintomático o prevaleciente es que, bajo la influencia de la UNAM, la mayoría de los programas abiertos por las universidades públicas y privadas desde 1951 hasta mediados de los años setenta del siglo pasado se hizo bajo el modelo de asociar el esquema de Ciencias Políticas y Administración Pública” (Alarcón Olguín 2010: 73).

México será el primer país de América Latina en la creación de una licenciatura cuya denominación será en un primero momento de ciencia política en la UNAM en el año $1951^{12}$ (Gutiérrez 2009, 2010 y 2011); haciendo lo mismo, en 1964, la Universidad Iberoamericana, institución perteneciente a la Compañía de Jesús. Este es un rasgo muy interesante en coincidencia con la Argentina ya que se observa la importancia que han tenido los jesuitas en el desarrollo de las ciencias sociales latinoamericanas fomentando una concepción que articula la investigación científica y la formación de excelencia con la propia acción política y social. Junto al desarrollo de instituciones de educación superior, la Compañía promovió la creación de los denominados Centros de Investigación y Acción Social (CIAS) que se fueron desarrollando en América Latina teniendo una enorme incidencia principalmente en las décadas del sesenta y setenta. ${ }^{13}$

La primera etapa del desarrollo disciplinar en México corre de 1930 a 1950 e incluye los principales antecedentes que definen el proceso de institucionalización de la ciencia. La segunda, entre 1951 a 1970, se inicia con la creación del primer Programa Académico de la Licenciatura en Ciencia Política en el país, ofertada por una institución educativa, a través de la fundación de la Escuela Nacional de Ciencias Políticas y Sociales (ENCPyS) de la Universidad Nacional Autónoma de México (UNAM) en 1951. Una vez puesto en marcha el primer Plan de Estudios en esta disciplina, el periodo se relaciona con tres actividades principales: la labor de una institución educa-

12 La UNAM abre la licenciatura que se denomínó Ciencias Políticas para 1951. Por una disputa dentro de la UNAM, la comunidad perteneciente a la escuela de economía impide la incorporación de la Administración Pública hasta el año 1958. Es importante resaltar el hecho de que la Administración Pública no fue integrada dentro de la estructura curricular en el inicio de los trabajos de la Escuela por la abierta resistencia de los economistas que defendían el derecho a discutir y reflexionar sobre los asuntos de la burocracia estatal, como lo refieren varios textos, por ejemplo, el de Sergio Colmernero, Historia, presencia y conciencia. Facultad de Ciencias Politicas y Sociales, 1951-1991, FCpyS-UNAM, México 1991.

13 El estudio de esta temática se encuentra en pleno desarrollo a partir del otorgamiento de la beca ICALA-Alemania con la investigación inicial La Compañía de Jesús y el desarrollo del pensamiento social en la Argentina durante la segunda mitad del siglo XX: entre la teoría y la acción social. Uno de los futuros objetivos conjuntos de investigación de los autores de este trabajo es la profundización de esta temática y el análisis comparado dentro de los países de la región.
El desarrollo de la ciencia política en Argentina, Brasil y México: construyendo una mirada comparada

Pablo Bulcourf Enrique Gutiérrez Márquez Nelson Cardozo 
tiva para formar especialistas que puedan incorporarse al mercado laboral e iniciar el ejercicio profesional como politólogos; la creación de un grupo especializado de docentes que reflexionaran en torno a la realidad nacional e inauguran el trabajo de investigación en la disciplina; el diseño y puesta en circulación de un órgano para difundir las investigaciones que realizaban algunos académicos mexicanos y también de propagar algunas contribuciones de autores extranjeros.

La tercera etapa del proceso va de 1971 a 1990. Sumado a este proceso se adiciona la tensión entre el derecho y las ciencias sociales de corte marxista que en aquel entonces discutían la autonomía de la política y pregonaban el desarrollo de una visión totalizante de las ciencias sociales críticas. Se pueden encontrar dos momentos importantes de expansión de la disciplina, con la creación de las licenciaturas en el ITAM y el Colegio de México, la creación del programa del CIDE y del ITESM, dentro de la región metropolitana de la Ciudad de México. Así mismo, la transición democrática también repercutió en la agenda de investigación y desarrollo curricular, incorporando un enfoque más transdisciplinar y más apartado de la originaria relación con la administración pública.

Durante este lapso, aparecen los estudios de posgrado en ciencia política y se marcaría un punto de inflexión para la disciplina al consolidar no sólo un espacio de conocimiento propio, sino al incorporar la tarea de investigación como un área de reflexión y generación de conocimiento permanente. Durante estas dos décadas, a la ampliación de la oferta educativa se agrega la expansión de la misma a través de la creación de licenciaturas en casi todos los estados de la República Mexicana, lo cual impactó también en un crecimiento de la matrícula y en un franco momento de consolidación disciplinaria. En las postrimerías del nuevo siglo, la ciencia política mexicana adquiere retos distintos e innovadores que resultan básicos para afianzar su consolidación. Este hecho inaugura una cuarta etapa identificada por el indudable lugar que ocupa la disciplina en el campo de las ciencias sociales - muestra de ello es el número de investigadores nacionales incorporados al Sistema Nacional de Investigadores (SIN) (Gutiérrez y Valverde 2013).

En el nivel de grado, Brasil cuenta con 14 licenciaturas en ciencia política. Por el contrario, en Argentina hay una gran cantidad de programas de grado que llegan a los 35, de los cuales 15 se encuentran en la ciudad de Buenos Aires y sus alrededores. La explicación a esa diferencia es porque, en Brasil, la ciencia política es una orientación en los cursos en ciencias sociales que se continúa en la maestría. A diferencia de ello, en Argentina, la ciencia política nace con las licenciaturas y presenta un desarrollo tardío en el posgrado. México es el país con la mayor cantidad de programas de grado en ciencia política de toda América Latina, contando con 87 cursos (Gutiérrez y Valverde 2013).

En lo que respecta a los posgrados, el escenario presenta una gran disparidad y heterogeneidad entre los países estudiados. En México encontramos que casi todos los doctorados tienen una perspectiva plural, siendo la ciencia política vista como una orientación. Del relevamiento realizado en el listado 
del Programa Nacional de Posgrados de Calidad (PNPC) de la CONACYT, encontramos que bajo el nombre de ciencia política solamente hallamos la maestría en ciencia política del Colegio de México (evaluado M, es decir de creación reciente) y el prestigioso doctorado de FLACSO-México en Investigación en Ciencias Sociales con mención en ciencia política (calificado D, es decir consolidado), receptor de una gran movilidad de estudiantes de toda la región. Por su parte, en la UNAM, se encuentra un Doctorado en Ciencias Políticas y Sociales, con cinco orientaciones, una de ellas en ciencia política.

La UAM ofrece una amplia variedad de doctorados, entre los que destaca la maestría en Estudios Políticos Sociales y el Doctorado en Ciencias Sociales con Orientación en Ciencia Política en específico, pero con la posibilidad de optar por materias que especialicen en la disciplina: un doctorado en ciencias sociales en Xochimilco, otro en Iztapalapa y uno reciente en Cuajimalpa; así también la Universidad Iberoamericana ofrece uno similar al de la UNAM. Fuera de la Ciudad de México está la Universidad de Guadalajara, con un doctorado en ciencias sociales con un enfoque más antropológico que sociológico, e incluso dónde la ciencia política casi no aparece.

En lo que respecta a Brasil, se invierte el patrón de todos los otros países, dado que hay un mayor número de posgrados en ciencia política que carreras de grado, reafirmando la idea que la formación como politólogo se realiza en la maestría y luego en el doctorado. Desde la creación de la primera Maestría en la Universidad Federal de Minas Gerais, hasta la reciente creación del curso en la Universidad Federal de Pelotas. Actualmente, hay 14 programas de Maestría en Ciencia Política en Brasil.

El organismo evaluador del posgrado - Coordinación de Evaluación y Perfeccionamiento de la Educación Superior (CAPES) tiene un gran poder regulatorio, con la capacidad de cerrar cursos, sometiendo a exigencias de acreditación muy fuertes, y solamente permite la creación de un doctorado con la consolidación de una maestría previa. En lo que respecta a la evaluación, con la nota máxima solamente existen los programas de la USP y el IUPER ${ }^{14}$, y seis con el concepto 6 . En cuanto al doctorado, Brasil cuenta con 9 programas. Uno de los principales desafíos que presenta el país, el de la expansión a nivel geográfica, se advierte por una concentración de estos programas en la zona centro-sur del país, ya que, en el eje Minas-Rio de Janeiro-San Pablo, de las 14 maestrías y de los 9 doctorados, 6 están en esta región.

En Argentina, actualmente existen 9 doctorados y 8 maestrías específicas en ciencia política. La diferencia que hay entre Brasil y Argentina, con la excepción de la Universidad Torcuato Di Tella, es que los programas de

${ }^{14}$ En lo que respecta al programa del IUPERJ en Río de Janeiro, uno de los más importantes de América Latina, en 2010 se produjo una masiva migración del cuerpo de profesores hacia la Universidad Estadual de Rio de Janeiro como producto de un conflicto laboral. No obstante ello, la institución mantuvo la nota en base al desempeño pasado, pero no refleja la composición del nuevo programa en base a los nuevos profesores.
El desarrollo de la ciencia política en Argentina, Brasil y México: construyendo una mirada comparada

Pablo Bulcourf Enrique Gutiérrez Márquez Nelson Cardozo 
doctorado y maestría no tienen articulación. Esto es por la naturaleza de la evaluación de la Comisión Nacional de Evaluación y Acreditación Universitaria (CONEAU) que no exige que una universidad dicte una maestría para crear un doctorado, sino que evalúa solamente a pedido de los programas. En este sentido, no tiene ningún poder para impedir el dictado de maestrías o doctorados, siendo el único límite la cantidad de inscriptos para poder seguir manteniendo su oferta.

\section{La construcción de redes}

Uno de los puntos donde convergen los cientistas sociales son las llamadas redes; esto se traduce en las asociaciones académicas de ciencia política a nivel nacional. En 1957, se creó la Asociación Argentina de Ciencia Política (AACP), presidida por Segundo Linares Quintana, el director de los Institutos de Derecho Público en la Facultad de Derecho en la Universidad de Buenos Aires y en la Universidad Nacional de la Plata. No obstante su sesgo juridicista, esta institución contribuyó en la consolidación de la ciencia política. En este sentido, se retomó la antigua "Revista Argentina de Ciencias Políticas", editando cuatro números de la revista. ${ }^{15}$ La continuadora como miembro de la IPSA es la Sociedad Argentina de Análisis Político (SAAP), que fue la red que aglutinó a los estudiosos de la política frente al rechazo de una incorporación masiva de estos por parte de la AACP en el año 1982.

En 1991, se llevó a cabo el Congreso Internacional de Ciencia Política que contó con 1400 participantes de 55 países, con más de 500 miembros de pleno derecho (socios graduados). Desde 1993, se desarrollan los Congresos Nacionales de Ciencia Política que se han transformado en el principal acontecimiento institucional de la disciplina en Argentina. En la última y undécima edición del mismo, celebrada en la Ciudad de Paraná, se ha contado con asistentes y ponentes de otros países, lo cual fue fomentado por la asociación al efectuar la convocatoria en portugués y definir que los idiomas del congreso sean el castellano, portugués e inglés. Otro aspecto interesante es que desde el año 2001 se permite la presentación de trabajos por parte de los alumnos, mostrando un crecimiento sostenido del número de participantes esta sección. Así mismo, los estudiantes de grado pueden sumarse a la sociedad como miembros adherentes, lo cual ha hecho crecer en términos cuantitativos a la institución en los últimos años, consolidando y profesionalizando la disciplina con un criterio federal. Cabe mencionarse la existencia de la Asociación Argentina de Estudios de Administración Pública (AAEAP), orientada hacia el desarrollo específico de esta área y en donde convergen tanto especialistas aca-

${ }^{15}$ La "Revista Argentina de Ciencias Políticas" fue creada en 1910 por Rodolfo Rivarola, siendo una publicación periódica de carácter bimestral; continuó su aparición ininterrumpida hasta 1928 (Bulcourf y D'Alessandro 2003). 
démicos como así también expertos y administrados gubernamentales, realizando sus encuentros también de forma bienal. En los últimos años ha surgido la Asociación Nacional de Politólogos (ANAP), de sesgo más profesionalista y con la construcción de una fuerte red federal.

La ciencia política brasileña confluyó en un primer momento en la ANPOCS, que es una asociación creada en 1977 para aglutinar y representar centros de investigación y programas de postgrado que actúan en el campo de las ciencias sociales. Con una participación inicial de catorce centros o programas, actualmente cuenta con 61 instituciones afiliadas que actúan en el área de la sociología, antropología y ciencia política. Al contrario de otras asociaciones científicas, ANPOCS afilia socios institucionales y no investigadores individuales. Como parte del proceso de autonomización, en el año 1986, se creó la Asociación Brasileña de Ciencia Política (ABCP), representante del país ante la IPSA que nuclea a los profesionales de ciencia política y estudiantes de posgrado de Brasil.

Si bien fue creada en 1986, su funcionamiento se reactivó en 1996, contando hoy con cerca de 500 socios, aproximadamente. Su encuentro nacional es realizado cada dos años. Además, la asociación promueve, apoya y participa con regularidad en eventos científicos diversos. $\mathrm{La} \mathrm{ABCP}$ tiene estipuladas tres categorías de socios: a) socios efectivos - maestrados o doctores que posean título equivalente o la más elevada en ciencia política mediante requerimiento de la directoria; b) socios estudiantes, alumnos regularmente matriculados en programas de posgrado estrictu senso en el área de ciencia política; y c) socios eméritos, personas que hayan dado una contribución significativa para el área, mediante propuesta presentada por tres socios efectivos, evaluada por la directoría y aprobada por la asamblea general. La asociación ha realizado a la fecha 9 congresos nacionales, habiéndose realizado el último en la ciudad de Brasilia.

Un singular escenario presentan las asociaciones profesionales en el país azteca. Contrariamente al proceso más corriente, que va de asociaciones de ciencias sociales, luego de ciencia política, para luego establecer núcleos por área, en el caso referido vemos que el proceso se dio de manera particular. Aunque existen dos referentes históricos con el Colegio Nacional de Ciencias Políticas y Administración Pública fundado en 1974, reconocido principalemnte por los administradores públicos, y la primera y original Asociación Mexicana de Ciencia Política fundada por Dr. Enrique González Pedrero en el año de 1980, las asociaciones mexicanas de la disicplina tardaron muchos años en madurar.

Paralelamente a éste proceso, podemos observar que para 1967 se crea la Asociación Mexicana de Estudios Internacionales como un grupo académico sobre esta temática, gracias a la iniciativa del destacado internacionalista Modesto Seara Vázquez. En 1998, se crea la Sociedad Mexicana de Estudios Electorales (SOMEE) ${ }^{16}$, con antecedente en el Grupo Especializado en Estudios Electorales del Consejo Mexicano de Ciencias Sociales (COMECSO) fundado

${ }^{16}$ Sociedad Mexicana de Estudios Electorales, más información disponible en: www.somee. org.mx
El desarrollo de la ciencia política en Argentina, Brasil y México: construyendo una mirada comparada

Pablo Bulcourf

Enrique Gutiérrez Márquez Nelson Cardozo 
Artículos y ensayos

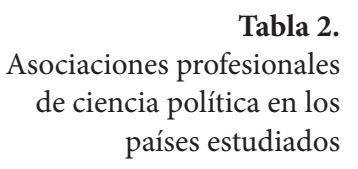

Tabla 2.

\begin{tabular}{|c|c|c|c|}
\hline Aspecto & Argentina & Brasil & México \\
\hline $\begin{array}{l}\text { Nombre de la } \\
\text { Asociación }\end{array}$ & $\begin{array}{l}\text { Asociación } \\
\text { Argentina de } \\
\text { Análisis Político } \\
\text { (SAAP) } \\
\text { (Existen también } \\
\text { otras dos } \\
\text { asociaciones } \\
\text { para considerar, } \\
\text { la Asociación } \\
\text { Nacional de } \\
\text { Politólogos ANAP } \\
\text { y la Asociación } \\
\text { Argentina de } \\
\text { Estudios de la } \\
\text { Administración } \\
\text { Pública AAEAP) }\end{array}$ & $\begin{array}{l}\text { Associação } \\
\text { Brasileira de } \\
\text { Ciência Política } \\
\text { (ABCP) } \\
\text { (Existe también } \\
\text { la Asociación } \\
\text { Nacional de } \\
\text { Posgrado } \\
\text { e Investigación en } \\
\text { Ciencias Sociales } \\
\text { ANPOCS) }\end{array}$ & $\begin{array}{l}\text { Consejo Mexicano } \\
\text { de Investigación } \\
\text { en Ciencia Política } \\
\text { (COMICIP) } \\
\text { Y } \\
\text { Asociación } \\
\text { Mexicana de } \\
\text { Ciencia Política } \\
\text { (AMECIP) } \\
\text { (Existe también la } \\
\text { Sociedad Mexicana } \\
\text { de Estudios } \\
\text { Electorales SOMEE) }\end{array}$ \\
\hline Año de creación & 1983 & 1986 & 2010 \\
\hline $\begin{array}{l}\text { Publicación } \\
\text { oficial }\end{array}$ & $\begin{array}{l}\text { Revista SAAP } \\
\text { Boletín SAAP }\end{array}$ & $\begin{array}{l}\text { Brazilian Political } \\
\text { Science Review } \\
\text { (virtual) }\end{array}$ & Revista AMECIP \\
\hline $\begin{array}{l}\text { Cantidad de } \\
\text { Congresos } \\
\text { realizados }\end{array}$ & 11 & 9 & $\begin{array}{l}2 \\
\text { (realizados por } \\
\text { AMECIP) }\end{array}$ \\
\hline
\end{tabular}

Fuente: Elaboración propia en base a datos de las diversas asociaciones.

en 1986. Esta asociación realiza la "Revista Mexicana de Estudios Electorales y el Encuentro Nacional de Estudios Electorales”, de manera ininterrumpida desde el año 1989 en forma anual. Otra asociación que vale la pena destacar es la Mexicana de Estudios Parlamentarios, que reúne a un destacado grupo de académicos e intelectuales de diferentes universidades de todo el país.

No obstante ese amplio desarrollo, no será sino hasta el año 2012 que se constituye el Consejo Mexicano de Investigación en Ciencia Política (COMICIP) que, sin duda, recupera los esfuerzos disicplinarios más importantes, tanto el del Colegio Nacional de Ciencias Políticas y Administración Pública, como el de la original Asociación Mexicana de Ciencia Política fundada por González Pedrero, con la incorporación en sus filas de los más destacados investigadores y académicos de las universidades más importantes y con el mayor prestigio y presencia en todo el país. En ese mismo año se crea también otra asociación llamada AMECIP que para el 2013 realizó el primer congreso de esta asociación 
en la ciudad de Guanajuato y su segundo evento en 2014 logrando su incorporación plena en la IPSA en este mismo año. Por su parte, el COMICIP realizó una serie de eventos y jornadas académicas más específicas, con expertos nacionales e internacionales, en varios estados de la República mexicana, entre los que destacan los eventos realizados con el comité de investigación número 33 de la International Political Science Association (IPSA), la Universidad de Colima, la Universidad Iberoamericana y la UNAM, entre otros.

\section{El desarrollo de la investigación institucionalizada}

En los casos estudiados han tenido una especial relevancia para el desarrollo de la disciplina los centros de investigación privados, sirviendo como un refugio frente a la expulsión del ámbito estatal que trajeron aparejadas las interrupciones institucionales en los países de la región (Bulcourf y D'Alessandro 2003; y Spina Forjaz 1997). De esta pauta se puede señalar que el caso mexicano constituye una excepción, dado que el gobierno del PRI fomentó el desarrollo de las ciencias sociales durante el siglo XX. El clima anticientífico fue una faceta más de la Doctrina de la Seguridad Nacional, en donde las ciencias sociales eran vehículos privilegiados para traer "ideas subversivas", bajo concepciones teóricas muy diversas.

Sin embargo, en el caso argentino, se mantendrá un florecimiento del mercado editorial representado por la editorial Paidós y EUDEBA en un primer momento, seguido por el Centro Editor de América Latina (CEAL) y el Grupo Editor Latinoamericano. El Instituto Torcuato Di Tella, fundado en 1958, que concentró el mayor número de especialistas hasta el advenimiento de la democracia en 1983, para el caso de Argentina; como así también el Centro de Estudios de Estado y Sociedad (CEDES); el Centro de Investigación en Ciencias Sociales (CICS) de la Fundación Bariloche o el Instituto de Desarrollo Económico (IDES) que publica la revista con el mismo nombre desde el año 1958, siendo la publicación científica con mayor continuidad del país. La Facultad Latinoamericana de Ciencias Sociales (FLACSO) en su sede argentina ha sido la institución pionera en la formación de posgrado en la década de 1970.

Por su parte, en el caso brasileño, el desarrollo de la ciencia política en la década de 1960 estuvo muy ligado al financiamiento de agencias internacionales, entre las que tuvo un papel muy relevante la Fundación Ford, la cual fue y en algunos casos continua siendo, el soporte financiero de algunos de los principales emprendimientos en el área: El Instituto Universitario de Investigaciones de Rio de Janeiro, el Departamento de Ciencia Política de la Universidad Federal de Minas Gerais; el CEBRAP, el CEDEC y el IDESP. El financiamiento estadounidense fue un intento de establecer una ciencia política de orientación pronorteamericana. Esa tesis ve el surgimiento de la politología como un proceso de formación de una elite intelectual capaz de influenciar las políticas públicas.
El desarrollo de la ciencia política en Argentina, Brasil y México: construyendo una mirada comparada

Pablo Bulcourf

Enrique Gutiérrez Márquez Nelson Cardozo 
En el caso brasileño, el proceso de "modernización conservadora" postuló un nuevo papel del Estado y para entender esa nueva esfera de actuación fue precisa la realización de estudios sobre la teoría del Estado. A razón de ello, las ciencias sociales se apartaron de la matriz norteamericana y francesa, atendiendo a cuestiones como el fundamento de la organización estatal, y volvió la atención de la academia brasileña hacia autores como Gramsci y Poulantzas, desligándose del paradigma funcionalista de la sociología norteamericana.

La diástole de la dictadura que se vivió a partir de la década de 1970 en el Brasil y "los resultados electorales de 1974 vieron movilizarse a la comunidad académica y, desde entonces, la investigación y publicación sobre instituciones políticas pasaron a constituir parte sustancial de la producción académica de la ciencia política"17 (De Lima Jr, 1999: 20). La vuelta a la democracia desde mediados de los años 80, significó el restablecimiento de las instituciones democráticas y republicanas, instalando el sistema básico de elecciones libres y competitivas, que permitió crear el clima de libertades necesarias para el desarrollo de la actividad científica. Esto implicó el inicio de un crecimiento continuo hasta nuestros días de la actividad politológica en la región. Tanto en Brasil, Argentina, Uruguay como en Chile, en este momento se inicia un proceso gradual de institucionalización y profesionalización de la disciplina.

En México se encuentran centros de importancia, donde sigue teniendo todavía una gran densidad la UNAM, seguida por el Colegio de México; destacándose también el CIDE, el INAP, la UAM, la IBERO y la FLACSO México, la Sociedad Mexicana de Estudios Electorales- un desprendimiento del Consejo Mexicano de Ciencias Sociales, entre diversos centros localizados en las universidades estaduales. Sin lugar a dudas, México ha representado en los últimos cincuenta años el centro más destacado de desarrollo de las ciencias sociales latinoamericanas, centrado principalmente en la sociología y en la antropología. A pesar de esto, en los años recientes, principalmente a partir de la vuelta de varios estudiantes de posgrado que realizaron sus estudios en los EEUU y Europa, la ciencia política ha tomado una fuerte autonomía y vitalidad.

\section{Las figuras de la ciencia política}

Desde mediados de la década de 1950 se empiezan a consolidar las ciencias sociales latinoamericanas con una impronta científica bajo la teoría de modernización, primero y con una respuesta crítica a sus postulados, a partir de los trabajos pioneros de Florestan Fernandes, Octavio Ianni y Fernando Henrique Cardoso en el Brasil; Gino Germani, Alfredo Poviña y Torcuato Di Tella en Argentina; Aldo Solari, Carlos Real de Asúa y Alberto Real en Uruguay; Pablo González Casanova y José Medina Echavarría en México; Manuel Garretón en

\footnotetext{
17 Traducción de los autores.
} 
Chile, que constituyen un claro ejemplo de institucionalización que marca un esplendor de las ciencias sociales latinoamericanas (Bulcourf y Caplan 2011).

Gradualmente, comienzan a destacarse estudios políticos de cientistas sociales argentinos, en donde tienen especial trascendencia la obra de Germani sobre los procesos de modernización en América Latina, seguido por otros investigadores, como Torcuato Di Tella y Darío Cantón. En lo que respecta a la ciencia política, Guillermo O’Donnell publica su libro Modernización y autoritarismo en el año 1972, tanto en inglés como en castellano, lo que lo convierte en el principal latinoamericanista que discutió las hipótesis "optimistas" de la teoría de modernización. O’Donnell llegó a ser presidente de la International Political Science Association (IPSA). En esta etapa tuvieron una gran relevancia Marcos Kaplan, José Nun y Marcelo Cavarozzi, además del rosarino Juan Carlos Puig, dentro de los estudios internacionalistas.

Entre los politólogos e internacionalistas argentinos que constituyen una referencia en el ámbito, podemos citar a Carlos Strasser, Oscar Oszlak, Carlos Escudé, Ernesto Laclau, Atilio Borón, José Nun, Natalio Botana, Liliana De Riz, Carlos Acuña, Bruno Bologna, Arturo Fernández, Eugenio Kvaternik, Roberto Russell, Catalina Smulovitz, Juan Tokatlian, Vicente Palermo, Gladys Lechini, Miryam Colacrai, Norberto Consani, Luis Aznar, Carlos Pérez Llana, José Paradiso, Aldo Isuani, Emilio Tenti Fanfani, Ana Maria Mustapic, Nélida Archenti, María de los Angeles Yannuzzi, Cristina Díaz, Daniel García Delgado, Isidoro Cheresky, Ernesto López, Enrique Aguilar, Julio Pinto, Alejandro Simonoff, Andrés Fontana, Mabel Thwaites Rey, Susana Villavicencio, Delia De La Torre, Néstor Legnani, Walter Cueto, Emilio Saguir, Mirta Guery, Susana Bonetto, Marcelo Camusso, Mónica de Corradi, Eduardo Salas, Amelia Barreda, Alberto Bonifacio, Nélida Perrona, Mercedes Kerz, María Cristina Menéndez, Raúl Arlotti, Guillermo Schweinheim, y Eduardo Arnoletto, como algunos nombres destacados.

En el caso de Brasil, el surgimiento de la ciencia política estuvo muy vinculado a las figuras de Wanderley Guilherme dos Santos y Fábio Wanderley Reis, con nombres tales como Bolivar Lamounier, Antonio Otávio Cintra, Simon Schwartzman, Amaury de Souza, Élcio Saraiva, Vinicius Caldeira Brandt, Edmundo Campos Coelho, Ivan Ribeiro, Francisco Weffort, Herbert José de Souza, Eli Diniz, Olavo Brasil de Lima Jr., Renato Boschi, Teotônio dos Santos, Maurício Cadaval. La principal característica de este grupo de investigadores era que rechazaban el paradigma de las ciencias sociales marxistas que desde mediados de la década de 1960 se tornó hegemónico, sobre todo en la sociología. Esto último se plasmó en los seminarios organizados por Fernando Henrique Cardoso, que nuclearon a jóvenes investigadores de la sociología, tales como Octávio Ianni, Juarez Brandão Lopes, Ruth Cardoso, Leôncio Martins Rodrigues, Fernando Novais, Paulo Singer, Bento Prado Júnior e Roberto Schwarz.

En los últimos años, muchos investigadores se volvieron relevantes tanto en su propio país como en el extranjero: vale la pena destacar a Argelina
El desarrollo de la ciencia política en Argentina, Brasil y México: construyendo una mirada comparada

Pablo Bulcourf Enrique Gutiérrez Márquez Nelson Cardozo 
Cheibub Figueiredo, José Álvaro Moises, Fabiano Santos, Jairo Nicolau, Regina Soares de Lima, Gláucio Soares, Miriam Saraiva, Octávio Amorim Neto, Sérgio Abranches, Luiz Bresser Pereira, Marcus Melo, André Marenco dos Santos, Williams Gonçalves, Clóvis Brigagão, Raquel Meneguello, Lucio Renno, María Herminia Taveres de Almeida, Leticia Pinheiro, Héctor Luis SaintPierre y Shiguenoli Miyamoto.

Entre los precursores de la disciplina en México es importante citar a Lucio Medieta y Núñez, Emilio Rabasa Estebanell, Raúl Carrancá y Trujillo, Manuel Germán Parra, y sus discípulos Enrique González Pedrero, Horacio Labastida, Francisco López Cámara, y Víctor Flores Olea. Las figuras destacadas de este período son Pablo González Casanova y Raúl Cardiel Reyes. El primer egresado de la carrera de la UNAM fue Moisés Ochoa Campos. A esta primera generación le sucedieron un conjunto de estudiosos, como Daniel Cosío Villegas, y sus seguidores: Moisés González Navarro, Enrique Krauze, Héctor Aguilar Camín, Vicente Fuentes Díaz, Octavio, Rodríguez Araujo, Daniel Moreno, Silvia Gómez Tagle, Jean Meyer, Luis Medina Peña, Gastón García Cantú, Arnaldo Córdova, Adolfo Gilly, y Javier García Diego. En nuestros días se pueden mencionar algunos destacados colegas como, Luis Aguilar Villanueva, Jacqueline Peschard, Francisco José Paoli Bolio, Luis Javier Garrido, Alberto Aziz Nassif, José Woldenberg, Rosa María Mirón Lince, Francisco Reveles Vázquez, Esperanza Palma, Gustavo Emmerich (recientemente fallecido), Guadalupe Pacheco, Andreas Schedler, José Antonio Crespo, Irma Méndez de Hoyos. A partir de la década de 1990 sobresalen personas como Luisa Béjar

Algazi, Benito Nasif, María Amparo Cásar, Luis Carlos Ugalde, Raúl Trejo, Ricardo de La Peña, Julia Isabel Flores, Francisco Abundis, Judit Bokser, José Luis Hoyo, Enrique Suárez Iñíguez, Fernando Castañeda, Nora Rabotnikof, José Luis Orozco, Joy Langston, Alejandro Moreno, Lorenzo Córdoba, Eric Magar y Gina Zabludovsky.

\section{Las principales obras}

La obra de Guillermo O’Donnell es, sin duda, la que más impacto ha tenido tanto en la Argentina como en América Latina; junto con Modernización y autoritarismo, el Estado Burocrático-Autoritario, y su participación como compilador en los famosos cuatro volúmenes de Transiciones. Tres libros continuaron compilando los aportes de O'Donnell: Contrapuntos, Disonancias y Catacumbas. En materia de relaciones internacionales, la labor de Carlos Escudé constituye uno de los mayores aportes de las ciencias sociales latinoamericanas al estudio de los fenómenos internacionales dado que creó una de las teorías críticas en la temática, su realismo periférico, expresado tanto en su libro homónimo como en El realismo de los Estados débiles. Dos libros han combinado la ciencia política con la dimensión histórica en la comprensión del proceso de construcción estatal, El orden conservador de Natalio Bota- 
na y La formación del Estado argentino de Oscar Oszlak. Debemos también mencionar el trabajo de Marcelo Cavarozzi Democracia y autoritarismo y la compilación de Carlos Acuña La matriz política argentina. Desde un enfoque fuertemente interdisciplinario sobresale el libro conjunto de Ernesto Laclau y Chantal Mouffe Hegemonía y estrategia socialista; y más recientemente del primero La razón populista.

Entre las principales obras producidas en México podemos mencionar, a modo de ejemplo, La democracia en México de Pablo González Casanova, El Sistema Político Mexicano de Daniel Cosio Villegas y La politización del niño mexicano, de Rafael Segovia; así como obras de alcance histórico como La ideología de la Revolución Mexicana de Arnaldo Córdova y La Revolución Interrumpida de Adolfo Gilly; escritos que orientan una ruta de trabajos tanto en la vertiente sociohistórica, empírica y de análisis institucional, como los campos principales cultivados en el país.

Dentro de los libros más importantes de la ciencia política brasileña están los trabajos de Olavo Lima Júnior con su estudio Partidos Políticos no Brasil: A experiência federal e regional: 1945-1964, publicado en el año 1983; la obra de Bolívar Lamounier y Fernando Cardoso Os partidos e as eleições no Brasil, de 1975; Sociedade e política no Brasil de Gláucio Soares; Que Brasil é este de Wanderley Guilherme dos Santos; Elites industriais e democracia de Renato Boschi; y Crise econômica e reforma do Estado no Brasil de Luíz Bresser Pereira.

Dentro del terreno de las revistas científicas, México ha sido la "decana" en la realización de revistas periódicas de ciencias sociales con la Revista Mexicana de Sociología, una referencia indiscutida en este campo producida por la UNAM. En este mismo rubro, con un sentido generalista y amplio, se ha destacado en la Argentina Desarrollo Económico y la revista Dados en Brasil; la primera publicada por el IDES y la segunda por el IUPERJ.

En el ámbito de la ciencia política en sentido más estricto se destacan en México las revistas: Revista Mexicana de Ciencias Políticas y Sociales, Política y Cultura, Andamios, Convergencia, Estudios Sociales, Gestión y Política Pública, Perfiles Latinoamericanos y Metapolítica.

A inicios de la década de 1990, surgieron en Argentina revistas de la especialidad, algunas de las cuales logran consolidarse en la década pasada, entre las que se encuentran PostData, Studia Politicae, El Debate Político, Revista Argentina de Ciencia Política, Temas y Debates, El Príncipe, Colección, Política y Gestión, Reflex, Nuevo Espacio Público. La revista PostData ha sido la primera que ingresó al núcleo básico de revistas del CONICET, regulado por el CAICyT, y fue ideada a fines de 1996 como una manifestación de la necesidad de articular el espectro científico académico de la ciencia política argentina en dos niveles.

La dirección de la Asociación Brasileña de Ciencia Política decidió crear una revista de Ciencia Política y Relaciones Internacionales titulada Brazilian Political Science Review (editada en idioma inglés), que circula solamente en formato electrónico y se presenta como una revista internacional. Otras pu-
El desarrollo de la ciencia política en Argentina, Brasil y México: construyendo una mirada comparada

Pablo Bulcourf Enrique Gutiérrez Márquez Nelson Cardozo 
blicaciones destacadas son: la Revista Brasileira de Ciências Sociais y Contexto Internacional. La Revista de Sociología e Política es una publicación semestral del área de Ciencia Política del Departamento de Ciencias Sociales de la Universidad Federal de Paraná, destacándose también la Revista Brasileira de Ciências Sociais (RBCS), publicada desde 1986, por la Associação Nacional de Pós-Graduação e Pesquisa em Ciências Sociais (ANPOCS).

\section{Entre interrogantes y conclusiones parciales}

A comienzo de los años 80 empiezan procesos de crecimiento sostenido en las ciencias sociales, entre las cuales se destacó la ciencia política, sobre todo, bajo el paradigma de la transitología. En Argentina, Brasil y México es donde cuantitativamente se ha desarrollado más la disciplina: en los tres países hay asociaciones profesionales integradas a la IPSA, realizan encuentros periódicos nacionales y hay varias revistas específicas de ciencia política. No obstante, resulta posible destacar algunas diferencias entre los casos estudiados. Posiblemente, la relación entre el campo académico y la dinámica política sea uno de los elementos más importantes a tener en cuenta. En México, la continuidad del PRI en el poder permitió la existencia de un modelo de reclutamiento político de corte civil, sin intervención militar, el cual se sustentaba ideológicamente en un ideario que pretendía ser "progresista" y "revolucionario", dando cabida y fomentando a los intelectuales. De hecho, México fue el país que más recibió exiliados pertenecientes a las ciencias sociales durante los períodos de dictaduras cívico-militares, en gran parte de los países de la región; por esta razón, en este caso hubo una enorme continuidad en el desarrollo de las ciencias sociales desde la década de los años 50, destacándose un proceso de autonomización paulatino de la ciencia política desde los años mencionados.

En Brasil, la ciencia política nació y se desarrolló en el posgrado como un área de especialización dentro de las ciencias sociales. Ese hecho también se vio en la tardía creación de la ABCP en 1986, lo que demuestra que la ANPOCS fue un espacio multidisciplinar de las ciencias sociales donde convivían la sociología, la antropología y la ciencia política. La dictadura militar, instaurada a partir de 1964, tuvo una orientación conservadora, pero modernizadora, fomentando la creación de universidades. Si bien existió una restricción de corte teórico-ideológico, disciplinas como la sociología se pudieron ir desarrollando. La autonomización del campo de la ciencia política se fue gestando en parte como producto de la constitución de una masa crítica de politólogos que rechazaban tanto el paradigma marxista como los estudios jurídicos, constituyéndose una disciplina independiente. Sin embargo, Reis plantea que no hay datos concluyentes para poder afirmar tal hipótesis, siendo prueba de ello los estudios críticos de la teoría de la modernización (Reis 2002). Desde la

década de los años 60 , la sociología política gozó de mucha relevancia dentro 
de las explicaciones a cuestiones centrales, tales como el desarrollo político y el Estado burocrático autoritario, sobre todo en Brasil y Argentina.

En un plano teórico, es muy interesante ver que cierta "autonomización" de la ciencia política estuvo vinculada tanto a su desprendimiento y desvinculación con el derecho y las visiones formalistas, como así también con el predominio de las concepciones marxistas prevalecientes en las ciencias sociales en la década de los años 60 más proclives hacia la sociología. La necesidad de explicar los procesos de transición democrática y la constitución de los sistemas de partidos y los sistemas electorales encontraron mayor "afinidad" con las vertientes del pluralismo norteamericano que con las perspectivas clasistas. A su vez, la influencia dirigencial es mucho más notoria en los estudios sobre el Estado, las burocracias públicas y las políticas públicas (Alford y Friedland 1991; y Bulcourf y Vazquez 2004). En este sentido, en los países con varias ofertas de grado y posgrado, se puede observar cierto "clivaje teórico-ideológico-metodológico" en donde ciertas instituciones de gestión privada suelen tener una orientación más hacia posiciones de "derecha" y en las universidades de gestión pública se observa una mayor pluralidad, en donde el marxismo y sus derivados siguen presentes, aunque esto no debe analizarse en esquemas rígidos o dicotómicos (Almond 1999; Bulcourf y Cardozo 2009).

El caso argentino y mexicano parecen ser, paradójicamente, opuestos al brasileño: se presencia una profusión de licenciaturas, 35 y 87 respectivamente, frente a un número limitado en Brasil - 14. Por el contrario, a nivel del posgrado, presentan una simetría en término del número de los programas. Esto muestra que el recorrido que siguen los cientistas políticos argentinos y mexicanos es diferente al que siguen sus colegas de Brasil. Primero hacen la licenciatura, para seguir luego en alguna área de especialización dentro de la ciencia política (administración pública, relaciones internacionales u opinión pública). En Brasil, el recorrido de los politólogos es el opuesto: se gradúan en ciencias sociales e inician su carrera académica en una maestría en ciencia política, siguiendo después el doctorado.

Los países presentan fuertes disparidades territoriales en términos de oferta académica. En Brasil, la ciencia política se concentra fuertemente en el eje Rio de Janeiro-Minas Gerais-San Pablo, y en Argentina está localizada en la capital y la región de Córdoba y el Litoral. Esa asimetría es todavía mayor en el posgrado donde el peso de la Ciudad de Buenos Aires es indiscutible, ya que concentra dos tercios de las maestrías y doctorados.

México presenta el desarrollo más grande a nivel de estudios de grado, distribuido territorialmente dado por la gran cantidad de programas de ciencia política en todo el país (87), tendencia inicial fuertemente vinculada a concebir a la ciencia política en relación a la administración pública. Los estudios de posgrado se presentan bajo una concepción fuertemente interdisciplinaria, similar a universidades públicas de Argentina, como es el caso de la Universidad de Buenos Aires. Por otro lado, la continuidad de la comunidad científicaacadémica de las ciencias sociales mexicanas ha sido la más perdurable de
El desarrollo de la ciencia política en Argentina, Brasil y México: construyendo una mirada comparada

Pablo Bulcourf Enrique Gutiérrez Márquez Nelson Cardozo 
América Latina, aunque han prevalecido disciplinas como la sociología y antropología más que la ciencia política. El margen de autonomía y la pluralidad de voces en México permitieron que se constituya en un foco de confluencia de las ciencias sociales durante los años de las dictaduras militares en gran parte de los países de la región, lo que constituyó el principal centro de aglutinamiento de científicos sociales e intelectuales.

Otro aspecto destacable son las características de las publicaciones científicas. En Argentina y México tenemos una presencia mayor de revistas académicas de ciencia política, mientras que en el caso brasileño el espacio editorial se encuentra compartido con el resto de las otras ciencias sociales (Politica e Sociologia, Dados, Revista Brasileira de Ciencias Sociais, Lua Nova), siendo creada en el año 2007 la Brazilian Political Science Review como un producto para la academia politológica internacional más que para el propio Brasil.

Argentina es el país que ha desarrollado los congresos con mayor número de participantes de la región en términos comparativos. En el caso brasileño son aplicados estrictos controles de calidad a la hora de evaluar la presentación de trabajos que lleva a la reducción del número de trabajos debatidos en los encuentros, mediante la aplicación de un referato más estricto a los resúmenes presentados.

El caso mexicano es muy particular en relación a las asociaciones de ciencia política, dado que se han desarrollado primeramente grupos vinculados a áreas temáticas que los que nuclean al conjunto de los politólogos, como la Sociedad Mexicana de Estudios Electorales o la Asociación de Estudios Legislativos.

La democracia ha traído un desarrollo, institucionalización y profesionalización mayor de la disciplina, no obstante lo cual hay un largo camino por recorrer. Sobre todo en la creación de revistas especializadas, desarrollo del posgrado y reconocimiento social de la disciplina. Cabe destacar que una "red de redes" es la Asociación Latinoamericana de Ciencia Política” (ALACIP), principalmente por la labor tesonera de Manuel Alcántara Sáez, su inspirador y creador junto al trabajo posterior de Glaucio Soares y Mariana Llanos, quien lo ha sucedido al frente de la asociación. La transferencia de la Secretaría Ejecutiva a Brasil y sus congresos posteriores en Buenos Aires, Quito y Bogotá demuestran la creciente internalización que está teniendo la ciencia política latinoamericana, lo que se expresa principalmente en las actividades que realizan la mayoría de los Grupos de Investigación.

Uno de los debates más interesantes que podemos plantear es la relación entre este "crecimiento" de indicadores ampliamente cuantificables y un "desarrollo" real del campo disciplinar. Las enormes asimetrías existentes dentro de la ciencia política latinoamericana hacia adentro de cada uno de sus territorios expresa también una enorme desigualdad cognitiva que reedita una relación "centro-periferia". El déficit de calidad institucional existente en materia de instituciones políticas (corrupción, independencia de poderes, mecanismos de control y convivencia del poder político con el crimen internacional transnacionalizado) son también un desafío hacia la propia ciencia política ya que 
expresa una enorme incapacidad en la transferencia de conocimientos para mejorar a estas instituciones. Esto, a su vez, no debe dejar de contemplarse en una interpretación más amplia de las relaciones entre Estado y sociedad, donde los países abordados siguen expresando sociedades con gran parte de su población en estado de pobreza y bajo la línea de necesidades básicas satisfechas, con enormes desigualdades socioeconómicas. Cabe la pregunta por el rol que ha tenido la ciencia política, tanto en la reproducción de este esquema, como así también en su colaboración para superarlas.

Por otra parte, el propio estudio sobre la historia, desarrollo y enseñanza de la ciencia política necesita una autorreflexión crítica y constructiva ya que sus resultados no son inocentes, generan un impacto en la forma con la cual reconstruimos nuestra propia historia, donde aparecen determinadas voces y otras son acalladas o ignoradas. Es necesario preguntarnos por los presupuestos básicos subyacentes que condicionan y orientan el desarrollo disciplinar y sus propias consecuencias políticas dentro y fuera de la comunidad científicoacadémica. Es necesario un estudio más profundo de la "política de la ciencia política”, como ha expresado en varios oportunidades Paulo Ravecca, lo cual nos lleva a preguntarnos sobre los complejos mecanismos de construcción del prestigio, el otorgamiento del presupuesto de investigación y la construcción de la propia agenda, los sistemas de incentivos y las becas que son otorgadas bajo el nombre de la "neutralidad del campo del saber y el conocimiento" (Ravecca 2010 y 1014). La manera en la que armamos el "rompecabezas" de la disciplina nos presenta mapas interpretativos muy disímiles y con enormes consecuencias dentro y fuera del propio campo (Fernández Ramil y Grebe Ramírez 2010). Necesitamos incorporar los aportes de la epistemología, la historia de la ciencia y la sociología del conocimiento en nuestros estudios para dar un paso hacia adelante en la comprensión de nuestra comunidad que amplíe los estudios orientados por una "descripción cuantitativa densa" de algunos indicadores bibliométricos de crecimiento. Es imperioso orientar nuestros quehaceres con una base historiográfica seria, ya que los datos no emanan de la "realidad" sino que son reconstrucciones siempre parciales con una enorme carga teórica e ideológica. Por esta razón es necesaria una constante "vigilancia epistemológica" sobre nuestro trabajo y afirmaciones. Este pequeño artículo es, simplemente, una invitación a preguntarnos sobre nuestra propia práctica, sobre nuestra historia, ese es el desafío.

\section{Bibliográfia}

Alarcón Olguín V. (2011), La ciencia política en México: trayectorias y retos de su enseñanza, Editorial Torres y Asociados, México.

Alford R. y Firedland R. (1991), Los poderes de la teoría, Manantial, Buenos Aires.

Almond G. (1999), Una disciplina segmentada. Escuelas y corrientes en ciencia política, México, Fondo de Cultura Económica.
El desarrollo de la ciencia política en Argentina, Brasil y México: construyendo una mirada comparada

Pablo Bulcourf

Enrique Gutiérrez Márquez Nelson Cardozo 
Altman D. (2005), La institucionalización de la ciencia política en Chile y América Latina: una mirada desde el sur, "Revista de Ciencia Política", vol. 25, no 1, pp. 3-15.

Altman D. (2011), Where is Knowledge Generated? On the Productivity and Impact of Political Science Departaments in Latin America, "European Political Science", vol. 11, no 1, pp. 71-87.

Blanco A. (2006), Razón y Modernidad. Gino Germani y la sociología en la Argentina, Siglo XXI, Buenos Aires.

Barrientos del Monte F. (2014), Buscando una identidad. Breve historia de la Ciencia Política en América Latina, Fontamera-UG, México.

Bourdieu P. (2003), Campo de poder, campo intelectual, Cuadrata, Buenos Aires.

Bourdieu P. (2008), Homo academicus, Siglo XXI, Buenos Aires.

Bulcourf P. (2007), Las nieves del tiempo platearon mi sien: reflexiones sobre la historia de la ciencia política en la Argentina, "Sociedad Global", vol. 1, no 1, pp. 7-35.

Bulcourf P. (2008a), Algunas reflexiones sobre la enseñanza de la ciencia política en la Argentina, "PostData", no 13, agosto, pp. 225-242.

Bulcourf P. (2008b), Almorzando con Gino: Germani y la política en la Argentina, "Revista Argentina de Ciencia Política", no 10/11, pp. 171-188.

Bulcourf P. (2012), El desarrollo de la ciencia política en la Argentina, "Política. Revista de Ciencia Política", vol. 50, no 1, pp. 59-92.

Bulcourf P. (2014), Una historia de marchas y contramarchas: la construcción de la ciencia política en la Argentina, "Iberoamericana", vol. XIV, no 56, Berlín-Madrid, pp. 169-174.

Bulcourf P., D’Alessandro M. (2003), La ciencia política en la Argentina, en: Introducción a la ciencia política, J. Pinto (comp.), Eudeba, Buenos Aires.

Bulcourf P., Vázquez J.C. (2004), La ciencia política como profesión, "PostData”, no 10, pp. 255-304.

Bulcourf, P., Jolias L. (2006), La historia de la ciencia política en la Universidad del Salvador, en: VV.AA. La ciencia política en la Argentina - 2006, Universidad del Salvador, Buenos Aires.

Bulcourf P., Cardozo N. (2009), Quien quiera oír que oiga: algunas reflexiones sobre la ciencia política argentina a comienzos del siglo XXI, "Espacios Políticos", año 10, no 5, pp. 30-31.

Bulcourf P., Cardozo N. (2010a), O desenvolvimento da ciência política na Argentina e no Brasil em perspectiva comparada, ponencia presentada en el $7 \mathrm{mo}$. Encontro ABCP Política, Desenvolvimento \& Inclusão Social no Brasil: Desafios da próxima década, Recife.

Bulcourf P., Cardozo N. (2010b), Ciencia política y relaciones internacionales en la Universidad Católica de Córdoba: una mirada sobre su desarrollo, "Studia Politicae", no 18, pp. 103-134.

Bulcourf P., Cardozo N. (2011), La fábrica de politólogos: la enseñanza de la ciencia política en la Argentina actual, "Espacios Políticos", no 6, pp. 11-12.

Bulcourf P., Caplan S. (2011), International studies in Argentina: some elements for its analysis, ponencia al Research Committee 33, Round Table, How can we improve our capacity to study politics? International Political Science Association (IPSA), Córdoba.

Cardozo N. (2010/2011), Del Centenario al Bicentenario: algunas reflexiones sobre el desarrollo de la ciencia política en los países del Cono Sur, "Revista Argentina de Ciencia Política", no 13/14, pp. 229-253. 
Cardozo N. (2014a), La ciencia política en Brasil, ponencia presentada en el 50 Aniversario de la Universidad Iberoaméricana, COMICIP-IBERO, México.

Cardozo N. (2014b), La ciencia política en Brasil, una historia en pujante desarrollo, "Iberoamericana", vol. XIV, no 56, Berlín-Madrid, pp. 186-190.

De Lima Jr. O. (1999), Partidos, eleições e Poder Legislativo, en: O que ler na ciência social brasileira 1970-1995). Ciencia Política (volumen III), S. Miceli (org.), Sumaré/ANPOCS, San Pablo.

Feres Jr. J. (2000), Aprendendo dos erros dos outros: O que a história da ciência política americana tem pra nos contar, "Revista Sociologia Política", no 15, noviembre, pp. 97-110.

Fernández A. (comp.) (2002), La ciencia política en la Argentina. Dos siglos de historia, Biebel, Buenos Aires.

Fernández Ramil, M.; Grebe Ramírez, C. (2010), Ciencia política e historia disciplinar: modelo para armar, "Politeia", vol 22, no 44, pp.1-30.

Ferreira Barbosa E. (2006), Desenho intitucional da ciência política no Brasil hoje, 2006, trabajo presentado en el Programa de Posgrado de la Universidad Federal Fluminense como requisito parcial para la obtención del grado de magíster en ciência política, Niteroi. Disponible en: http://www.uff.br/dcp/wp-content/uploads/2011/10/Disserta\%C3\%A7\%C3\%A3o-de-2006Elton-Ferreira-Barbosa.pdf

Flores-Mariscal J. (2011), El desarrollo de la ciencia política en México. Una mirada a través de los estudios sobre el estado de la disciplina, UAM, México, disponible en: http://works. bepress.com/jr_joel_flores_mariscal/24

Giddnes A. (1987), Las nuevas reglas del método sociológico, Amorrortu, Buenos Aires.

Guardamagna M. (2008), La ciencia política en Cuyo: el auge antes de la crisis, ponencia presentada en el VIII Congreso Nacional de Democracia, Rosario.

Gunnell J. (2006), The Founding of the American Political Science Association: Discipline, Profession, Political Theory, and Politics, "American Political Science Review". Vol. 100, no 4, November, pp. 479-483.

Gutiérrez Márquez E. (2009), La Ciencia Política como una ciencia social y espacio de interacciones, en: Teorías y problemas contemporáneos, Reflexiones desde la ciencia política, M. E. Romero Ortiz, K. Valverde Viesca (coord.), UNAM- Universidad de Colima, México.

Gutiérrez Márquez E. (2010), La Ciencia Política Académica en México, campo de interacciones sociales, en: ¿Cómo Investigamos? México, C. Gallegos Elías, R. María Lince (coord.), Editorial UNAM, México.

Gutiérrez Márquez E. (2014a), Importancia de las dimensiones teórica y metodológica en la formación profesional de la ciencia política, UNAM-FCPyS-DGAPA y Ediciones la Biblioteca, México.

Gutiérrez Márquez E. (2014b), La ciencia política en la Facultad de Ciencias Políticas y Sociales de la UNAM, en La Ciencia Política en México Hoy: ¿Qué sabemos?, F. Reveles (coord.), Editorial UNAM y Plaza y Valdés, México.

Gutiérrez Márquez E. (2014c), Algunas pinceladas que explican el desarrollo de las ciencias políticas en México, “Iberoamericana”, vol. XIV, no 56, Berlín-Madrid, pp. 175-180.

Gutiérrez Márquez E., Marcos P (2010), Ciencias políticas, en: La UNAM por México, M. Lourdes Chehaibar Náder (coord.), UNAM, México.

Gutiérrez Márquez E., Valverde Viesca K. (2014), El proceso de institucionalización de la ciencia política a 70 años de su desarrollo en México, en: La ciencia política en América
El desarrollo de la ciencia política en Argentina, Brasil y México: construyendo una mirada comparada

Pablo Bulcourf

Enrique Gutiérrez Márquez Nelson Cardozo 
Latina: docencia e investigación en perspectiva comparada, F. Freidenberg, Ediciones FUNGLODE, Santo Domingo, República Dominicana. (en prensa)

Leiras M., Abal Medina J. M., D'Alessandro M. (2005), La ciencia política en la Argentina: el camino de la institucionalización dentro y fuera de las aulas universitarias, "Revista de Ciencia Política”, vol. 25, no 1, pp. 76-91.

Lesgart C. (2003), Usos de la transición a la democracia. Ensayo, ciencia y política en la década del '80, HomoSapiens, Rosario.

Lesgart C., Ramos M. J. (2002), La temprana creación del estudio universitario de la política en Rosario. Itinerarios institucionales, en: Ciencia politica en Argentina. Dos siglos de historia, A. Fernández (comp.), Ediciones Biebel, Buenos Aires.

Lessa R. (2010), O campo da ciência política no Brasil: una aproximação construtivista, en: Horizontes das ciências sociais no Brasil, C. B. Martins (coord.), ANPOCS, Sao Paulo.

Limongi F. (1999), Institucionalização política, en: O que ler na ciência social brasileira 1970-1995). Ciencia Política (volumen III), S. Miceli (org.), Sumaré/ANPOCS, Sao Paulo.

Melo M. (1999), Estado, gobernó e políticas públicas, en: O que ler na ciência social brasileira 1970-1995). Ciencia Política (volumen III), S. Miceli (org.), Sumaré/ANPOCS, Sao Paulo.

Ravecca P. (2010), La política de la ciencia política: Ensayo de introspección disciplinar. Desde América Latina Hoy, "Revista América Latina. Revista de Doctorado en Procesos Sociales y Políticos en América Latina, no 9, pp. 173-210.

Ravecca P. (2014), La política de la ciencia política en Chile y Uruguay: Ciencia, Poder y Contexto. Hallazgos desde una agenda de investigación, Documento de Trabajo, Instituto de Ciencia Política de la Universidad de la República, no. 1, Montevideo.

Rehren A., Fernández M. (2005), La evolución de la ciencia política en Chile: un análisis exploratorio (1980.2000), "Revista de Ciencia Política”, vol. 25 no 1, pp. 40-45.

Reis E. (2002), Situando a sociologia política. Entrevista em Política e Sociedade, "Revista de Sociologia Política", vol. 1, no. 1, pp. 11-35.

Reis F. W. (1999), Institucionalização política (comentário critico), en: O que ler na ciência social brasileira 1970-1995). Ciencia Política (volumen III), S. Miceli (org.), Sumarél ANPOCS, Sao Paulo.

Reis F. W. (2002), Sociologia política, Ciência política e éscolha racional, "Revista de Sociología Política", vol. 1, no 1, pp. 37-55.

Santos F., Amorin Neto O. (2005), La ciencia política en Brasil: El desafío de la expansión, "Revista de Ciencia Política", vol. 25, no 1, pp. 1001-1010.

Spina Forjaz M. C. (1997), A emergência da ciência política no Brasil: aspectos institucionais, "Revista Brasileira de Ciências Sociais", vol. 12, no 35, febrero, San Pablo. Disponible en: $<$ http://www.scielo.br/scielo.php?script=sci_arttext\&pid=S0102-69091997000300007\&ln $\mathrm{g}=\mathrm{en} \& \mathrm{nrm}=\mathrm{iso}>$. ISSN 0102-6909. http://dx.doi.org/10.1590/S0102-69091997000300007

Trinidade H. (2003), Introducción, en: Las ciencias sociales en América Latina, H. Trinidade (coord.), Siglo XXI, México.

Trent J. (2008), Issues and Trends in Political Science at the Beginning of the $21^{\text {st }}$ Century: Preliminary Perspectives from the World Political Science Book Series, paper presentado a la International Political Science Association Conference - International Political Science: New Theoretical and Regional Perspectives, abril-mayo, Montreal. 